\title{
Allocating resources in mental health: a clinician's guide to involvement
}

\author{
Mark Davies
}

Abstract With fundamental changes to the way services are commissioned and resourced within the UK's National Health Service (NHS), optimising the efficient and effective use of resources has become a key task for mental health clinicians and managers. A core step in this process is ensuring that resources are optimally allocated across the service. This article outlines steps in resource allocation, including understanding how resources are managed through budgets, the link between resource matching and care delivery, and methods of reallocating resources to improve service performance. Influencing appropriate allocation is a critical role for psychiatrists, working with both managers and commissioners in the decision-making process. Understanding resource allocation from a management perspective should improve the ability of psychiatrists to influence this process more effectively.

As mental health services in the UK continue to evolve in line with wider National Health Service (NHS) modernisation, one of the key managerial challenges is the more effective and efficient use of limited resources. With the introduction of new mechanisms for resource decision-making such as payment by results and practice-based commissioning (Department of Health, 2004), pressure on services to manage and allocate resources for greater productivity and performance will increase. As key decision-makers in the use of service resources and the management of the care pathway, psychiatrists have a critical role in ensuring that resources are allocated optimally (Ruta et al, 2005). This is supported by the General Medical Council, which states that 'as managers, doctors must allocate resources in the way that best serves the interests of a community or population of patients' (General Medical Council, 1999: para. 7). Understanding how resources are allocated from a management perspective is therefore vital if psychiatrists are to take an active part in shaping mental health services of the future and ensuring that quality is maintained in the face of ever greater pressures to reduce costs.

\section{What is a "resource"?}

Resources are the basic building blocks of organisations and they fall into a number of core categories (Box 1). Resourcing is a relative concept.
For a given organisation, for example a mental health service, whether a person is a resource or not is defined by the ability of that person to contribute to the delivery of the organisation's strategic purpose and objectives. For example, in the development and delivery of a specialist service for younger people with dementia, only a subsection of clinicians and managers with the relevant capabilities, skills and, indeed, availability would be considered a resource. This implies that resources in one service area are not always transferable into other areas.

Resources may be considered on an individual, team, organisational or network level. A key focus for managers is how resources and their allocation contribute to the performance of an organisation or team, where performance is defined as the organisation's ability to manage resources to deliver objectives. Ultimately, this performance will depend on what resources are available and how they are allocated and managed (Kaplan \& Norton, 1992).

\section{Resource allocation: basic concepts The three Es}

How resources are allocated in a mental health service will depend on a number of complex factors. Some of these, for example government policy, will be largely beyond the control of clinicians and managers.

Mark Davies is an honorary consultant psychiatrist and Director of Res Consortium (Fosse House, East Anton Court, Icknield Way, Andover SP10 5RG, UK. Email: mdavies@resconsortium.com), an organisation working with the NHS and industry on performance improvement. He left clinical practice to take an MBA at Bath University School of Management, and has worked with clinicians and managers on all areas of joint working in service design and development. He has a research interest in network performance and methods of engaging professional groups in service development and commissioning processes. 


\section{Box 1 Main types of resources}

Human resources - otherwise known as people. Evidence from both the public and private sectors on the performance of people suggests that the three key elements in making people an effective resource are ability (they are able to do the job), motivation (they want to do the job) and opportunity (they are allowed to do the job) (Purcell et al, 2003)

Knowledge - critical for effective decisionmaking and ultimately based on knowing. Data and information are an essential element, but knowledge relies on these being both relevant and accessible. Therefore if information technology (IT) is to support knowledge, IT systems must be actively integrated with clinical practice (Sensky, 2002)

Finances - underpin and define the availability of most other types of resources. Usually presented in the form of a budget. Although some believe that policy sets budget, in practice the reverse is often the case

Buildings - a physical location is a vital resource for organisations. It is often the most expensive resource because of high fixed costs that do not vary despite varying the use, or level of activity, associated with the resource

Time - a key personal resource. Often overinvested in being reactive to demands. In a demand-led organisation such as the NHS little time is available to be proactive, for example planning and reflecting on more efficient methods to meet demand. Optimal time management means investing in at least some proactive time

Goodwill and trust - often viewed as the softer end of people management. However, research suggests that a high level of trust is a resource that improves communication and efficiency and ultimately increases overall team and service performance (Lane \& Bachmann, 2000)

However, other factors will be more controllable, for example how existing resources are allocated across a service. Time, itself a resource, may be better spent focusing on these more controllable areas. A common starting point for decisions concerning resource allocation is based on the what Daniels (2000) describes as the three Es, which bring ethical and economic considerations together:

- Equity - does the allocation achieve fairness as defined by agreed parameters such as health status, utilisation of services and access? For example, for all patients with a comparable diagnosis of schizophrenia, are resources focused on enabling comparable access to appropriate therapies?

- Effectiveness - how well are outcomes achieved? For example, for patients with a diagnosis of dementia, are resources actually achieving improvements in functioning?

- Efficiency - how well are resources used to produce a given output? For example, for a local acute liaison service (where certain service-level outcomes have been agreed), could the same standards be achieved with fewer resources through optimisation? This might involve cost-cutting, where resources are lost altogether, or be cost-neutral, where resources are kept within the service but used to better effect elsewhere. A key point to bear in mind is that cost-cutting is not in itself equivalent to optimisation.

\section{Budgets}

Resources are usually identified within an associated budget. A budget is a plan for achieving objectives which is stated in monetary terms. Budgets can be distinguished from income, which is the absolute flow of funds into the service. Budgets simply allow funds to be allocated to specific service areas, and provide a means of accountability for resource management (Cook, 1995). Budgets may have multiple sources, and often carry conditions of use (ring fencing) regarding the types of service models that can be resourced. For example, a community mental health team may be staffed from its own core budget, but benefit from additional workforce resources such as seconded therapists and primarycare-commissioned link workers paid by other bodies.

Increasingly, local commissioners are likely to set mental health budgets for specific services and types of resource use. There is a significant relationship between budgeting and the three Es. If adequate funding is not available, and yet the objective is to meet demand, subclinical levels of care or inappropriate services might result and outcomes might not meet expectations (ineffectiveness). If appropriate interventions are not funded, outcomes may take longer to attain, resulting in higher costs to both the mental health system and society as a whole (inefficiency). Both scenarios can result in inequity. In some areas of mental health, standards of care may not have been defined sufficiently to clearly make the case for achieving measurable outcomes. This makes effectiveness of resourcing harder to prove or disprove. Some may argue that psychiatrists should 
therefore work harder at defining local outcomes in terms of quality and resource utilisation, both for resource management and, in future, to inform the commissioning process (see below).

For managers, three key questions are:

- How can sufficient budgets be identified to finance service plans?

- How can those funds be allocated to meet defined needs and priorities?

- How can the cost of care be controlled? (adapted from Funk et al, 2003).

Budgets define the availability of key resources such as people and buildings. However, it is difficult to place a financial value on other types of resource, such as knowledge, goodwill and trust. This means that focusing on budgets alone as a method of defining resource priorities may not always improve overall performance.

\section{Costing options}

Anumber of approaches can be employed to consider the best way for resources to be allocated (Shah \& Jenkins, 2000). For example, cost-benefit analysis identifies the present value of net costs and benefits, and attempts to obtain the greatest benefit at least cost. Thus, in the planning of an early-intervention psychosis service, a cost-benefit analysis may involve defining the benefits in terms of outcomes (e.g. detecting a certain number of young people with a psychotic disorder who would otherwise remain untreated) and then defining a range of options for the care pathway that will deliver this benefit. These options would be costed and a preferred (i.e. cheapest) solution identified.

When allocating resources using a specified budget, certain aspects need to be considered: the opportunity cost; fixed and variable costs; and the margin.

\section{The opportunity cost}

Allocation of resources to one service results in the loss of some opportunity for benefit that might have been achieved had those resources been invested elsewhere. This is known as the opportunity cost. For example, shifting the focus of mental healthcare to primary care services in certain areas, although having potential advantages, may carry an opportunity cost of less investment in secondary care.

Fixed and variable costs

Fixed costs are those that stay essentially the same despite changes in activity. For example, most of the costs of an in-patient bed are linked to the hospital building and staffing. These stay essentially the same whether the ward is almost empty or full. Variable costs, on the other hand, vary with activity. This is important, as budgets usually already have fixed costs included. For example, a budget for a specialist clinic might allocate $80 \%$ of its funds to fixed costs (e.g. buildings, staff's basic salary) and $20 \%$ to variable costs (e.g. staff overtime, additional staff to cover for holidays).

\section{The margin}

A margin is the addition or subtraction of funds in an existing budget. Changes in the margin have differing effects on fixed and variables costs. Using the example in the previous paragraph, an increase in the overall budget of $10 \%$ will have proportionately greater impact on variable costs (as fixed costs are already covered). In turn this should translate into a proportionately higher budget for variable costs and therefore activity (in this case around $50 \%$ ). What to do with margins is a key issue for managers.

Even if there is no marginal change, the manager should still consider how resources might be best moved from one part of the service to another to make them more efficient and effective (cost-neutral performance improvement).

\section{Outcomes v. outputs}

A key tension in healthcare that often drives disputes is that between management staff as general resource managers and clinicians as specific resource managers (Fig. 1).

The operational focus of most clinicians is on meeting patients' needs, with priority given to medical outcomes such as relapse rates. Management staff, however, are under significant pressures imposed by contractual agreements and other forms of external monitoring to focus on output (e.g. the number of patients handled and bed occupancy) and financial performance for whole populations (Ballantine et al, 1998). Building a local mechanism for managing this relationship towards dialogue rather than conflict is vital for high service performance and good quality of care.

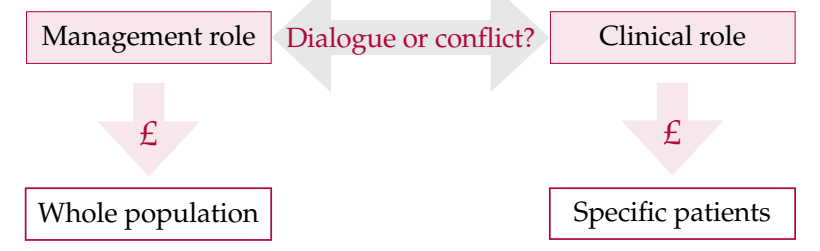

Fig. 1 Relationship between management and clinical resource allocations. $£$, funds. 


\section{Productivity}

Finally, consider the notion of productivity. Productivity is essentially a measure of performance relating mostly to people. In a mental health service, greater productivity means that more healthcare, however defined, is delivered by staff for a given set of resources. Many important resource allocation decisions will involve matching people to the parts of the organisation where their productivity is likely to be maximised. This will mean taking into account their ability, motivation and job opportunity. Related issues to consider include the skill mix, cost containment, role redesign (see New Ways of Working, in 'Integrating key processes' below), managing staff shortages and inequities, and requirements for new service models (Buchan et al, 2000).

With greater NHS focus on resource management, an interesting and increasingly pertinent question is how one demonstrates the productivity of psychiatrists, managers and others in a mental health service. Productivity measures are required not simply to show that productivity can be driven even higher. If it is already high and it can be shown that there is no more flexibility in the system, i.e. resources are already optimally allocated, the business case is strengthened for greater total resourcing.

\section{Local allocation of resources: the service pathway}

As resources are defined relatively, a framework for care delivery with agreed objectives needs to be in place before resource allocation begins. Clinical care is generally delivered through formally (or informally) developed care pathways, which define the types of care intervention required for specific patient groups (Eccles \& Mason, 2001). With the growing focus on resource management and infrastructure (such as information systems and buildings), care pathways are evolving into service pathways, which stress both the model of care delivery and the resources required to deliver that care. For example, developing a team to care for people with learning disabilities in the community will require not just a set of interventions delivered by clinicians and other care professionals, but also a management system that includes policy development, a team base, information systems, budgeting and performance management.

To build an effective service pathway those involved must be clear on the need for that service, on standards of care and on key performance indicators. It seems to me that most people are not clear on the need for their service, met or unmet. The service pathway model provides a common mechanism for clinicians, managers and ultimately commissioners

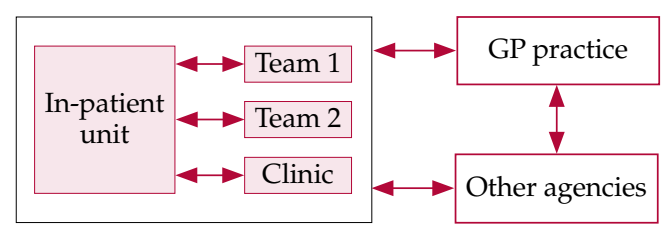

Fig. 2 Examples of components of a service pathway.

to work together to define how effective, efficient services can be planned, funded and delivered. If you were to envisage your own service in terms of a service pathway similar to that shown in Fig. 2, would you find that resources (e.g. people, knowledge and buildings) are optimally allocated? This exercise is about shifting resources, not cutting costs.

Once the pathway is worked out the key task for local services is to decide, for given budgets, how resources are best allocated to its components. The wider impact of resource allocation must also be appreciated, including opportunity and marginal cost issues. For example, allocation in favour of community mental healthcare can lead to higher than intended spending on out-of-area placements (Tyrer et al, 1998).

\section{A word on commissioning and business planning}

As the NHS evolves, planning and funding of services has been devolved to local commissioning processes. The principle of commissioning is essentially the purchase of defined packages of healthcare for a defined population or patient group. For example, local commissioning might be used to set up a general adult service covering common conditions that do not require tertiary services, whereas more specialist commissioning might be required for services such as forensic care, or for particular conditions such as eating disorders.

The NHS is now open to 'plurality of provision' (care provision from a range of different sectors, including private and voluntary as well as public), which might force local mental health services to compete for funding with providers in the independent sector (Department of Health, 2005a). Consequently, the involvement of psychiatrists in the commissioning of mental health services is essential to ensure that resources do actually meet the needs of people with mental illnesses (Simpson, 2000).

\section{Practice-based commissioning}

Responsibility for commissioning much of local service provision is being transferred from primary 
care trusts (PCTs) to general practitioners (GPs) and other senior primary care clinicians through a process known as practice-based commissioning (Department of Health, 2004). The rationale here is to move from centrally defined block contracts (whereby variation in activity was not necessarily reflected accurately in received funding, or income) to a more local focus identifying specific levels of activity, the 'packages of care' delivered and the funding received.

The packages of care delivered, called healthcare resource groups, ${ }^{1}$ will be given a standard price called the national tariff. Simply put, this means that for an average person with $x$ condition and $y$ level of functioning a certain healthcare resource group will be triggered that will carry the same price, wherever the individual receives this care. This means that understanding the cost of care in a local service is very important. For example, psychiatrists increasingly need to have an idea not only of the therapeutic interventions available for, say, a person with schizophrenia, but also the costs of these interventions and a view on whether resource management within the care pathway can be improved.

\section{Reference costs}

Currently the efficiency of services in delivering healthcare is measured by reference costs, whereby each NHS trust is benchmarked to a national average for cost of care (Department of Health, 2005b). From a management perspective, more interesting is the relative cost of each service within a trust: some may push up the trust's overall reference cost by being inefficient, whereas others may bring it down by being more efficient. For example, a liaison service and a bipolar service in the same trust may have different levels of efficiency and therefore have differing impacts on the trust's overall reference cost.

The relevance here for psychiatrists is that reference costing will have a direct impact on the ability of services to meet commissioning contracts in the future. High reference costs indicate likely future pressure to achieve significantly greater efficiency in use of resources, and potential cost-cutting. Service providers will eventually be funded on the basis of their performance in delivering care to a certain number of patients specified by healthcare resource groups, a system known as payment by results (Department of Health, 2004) (Fig. 3).

1. These have yet to be fully defined for mental health services. Further information will appear on the NHS Health \& Social Care Information Centre website (http://www.ic.nhs.uk) in due course.

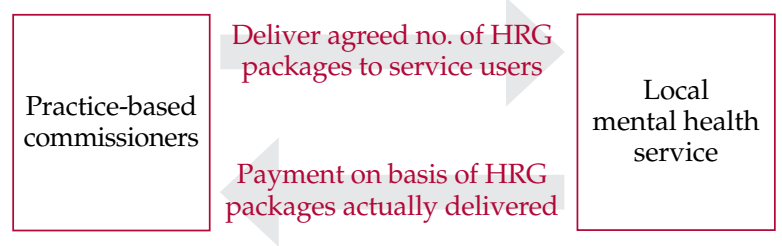

Fig. 3 Principles of the new NHS commissioning system. HRG, healthcare resource group.

\section{Business planning}

The implications of these factors are that mental health service clinicians and managers must work together to manage tensions between clinical models of care and service cost drivers. A key process for achieving this joint working is business planning. Business planning involves defining proposed future services in terms of objectives, required resources, costs and performance indicators. Effective business planning will be a key factor influencing commissioners, along with high levels of trust and a willingness to be flexible in negotiation. A key feature of business planning is identification of how resources should be allocated to deliver objectives (Bennett, 1994). Increasingly psychiatrists need to understand the principles of business planning in order to influence how services will be commissioned and delivered.

Box 2 shows the key questions that should be asked during the business planning process.

\section{Building a local resource allocation approach}

Given the range of resourcing pressures on mental health services and the move towards more local commissioning and resource management, an 'inservice' method of optimising resource allocation is essential. Often the process of resource allocation

\section{Box 2 Key questions for business planning}

- What are the vision, purpose and objectives of this service?

- What resources (people, information and buildings) are required?

- What do these resources cost (what budgets do we need)?

- What is the best way to allocate them?

- Who will pay for this proposal?

- What are the measures of success (and failure)? 
is not clearly defined within local services (Butler, 1999). To establish an appropriate local process it is necessary to identify the potentially conflicting values, needs and interests of the stakeholder groups and to create from these a workable set of local principles (Björk \& Rosen, 1993). The stakeholders should include representatives of all the clinical professionals involved (who will tend to hold similar values regarding resource allocation) (Myllykangas et al, 2003).

Clinicians may 'know in practice' how resource allocation should occur (Schon, 1983) but this needs to be translated into clear and accessible business cases or proposals. A variety of approaches can be used to build this process, including variants of zero budgeting (Kren, 1992) and programme budgeting and marginal analysis (Mitton \& Donaldson, 2004). In essence these methods are based on the set of common themes shown in Box 3.

\section{Box 3 Building a simple resource allocation} system

1 Establish a coalition with consensus on key needs - include staff, commissioners and service users, and try to use existing forums to avoid creating yet more meetings

2 Define service objectives - on the basis of identified local needs and national, local and commissioning priorities

3 Audit existing resources - through process mapping the service pathway and including analysis of cost and comment on efficiency. Existing audit facilities may come in useful

4 Agree priorities - agree potential options for investment, on the basis of research, economic evaluations, best practice and local data, as well as expert opinion. These options must be ranked on the basis of key criteria such as health gain, accessibility, innovation, staff retention/recruitment and system integration. Identify areas of service growth and, to fund proposed growth, areas for 'resource release' (Cohen, 1994)

5 Implement and manage change - including engaging staff in service reconfiguration. This is a key challenge and staff must be involved as early as possible

6 Review - monitoring performance of areas receiving resources is essential to ensure that the opportunity cost does not become too high. Review may lead to further reallocation, forming a cycle of activity

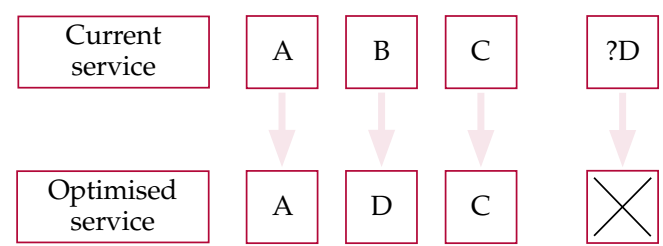

Fig. 4 Using cost-neutral reconfiguration to optimise service resource allocation. A-D, service pathway components.

The level of resourcing made available to each service to develop service pathways will determine whether, for example, more primary care aspects of the service or additional early-intervention services are developed (Thornicroft \& Tansella, 2004). These different service models are likely to vary in their requirements for resources.

As an illustration, consider a service pathway to treat people with depression, which has key components A, B and C (say, a ward, a community team and a clinic). Another component, D (perhaps a primary care-based cognitive-behavioural therapist), might be added, but there might be an opportunity cost in developing it. If no additional resources were available, would the service overall benefit from developing $\mathrm{D}$ by a shifting of resources from one of the existing components? In other words, can a costneutral service reconfiguration be found? (Fig. 4)

Managing a change of optimisation is not without significant challenges, and the task should not be underestimated. Evidence suggests that problems in achieving optimal resource allocation include lack of financial data, the difficulty of predicting budgets for patients with long-term conditions and the identification of unmet need. These are linked to resistance to disinvestment, lack of trust between stakeholders, and lack of economic knowledge and experience (Mitton \& Donaldson, 2003). A key factor in successful resource allocation, and one that is understandably challenging, is a commitment to look at 'sacred cows': areas of low performance but high emotional attachment.

\section{Integrating key processes}

The function of optimising resource allocation is closely associated with four key processes relevant to psychiatrists: appraisal, job planning, the New Ways of Working initiative and clinical governance.

\section{Appraisal}

Standard appraisal may identify the need for improvement in skills such as understanding budgets and costs, working with commissioners 
and managing resource performance. Learning of these skills may be usefully incorporated into the psychiatrist's professional development plan.

\section{Job planning}

Setting the right objectives, and ultimately the right job plan, must take into account overall service pathways and planning priorities. The individual's job plan focuses their resources, including time and knowledge, to meet personal and service objectives. For example, a psychiatrist might be able to integrate a special clinical interest in chronic fatigue with the service objective of offering commissioners more primary care-based interventions for people with chronic fatigue disorder. The 'collective' of the job plans of all the psychiatrists in a service must be effectively coordinated and focused.

\section{New Ways of Working}

This initiative, introduced by the Department of Health, relates to reviewing current practices across service teams with a view to agreeing the optimal allocation of people to tasks. This may involve variable levels of change at individual and team level (Royal College of Psychiatrists \& National Institute for Mental Health in England, 2005). For example, it might be more efficient if consultants were to devolve certain roles (such as certain types of patient followup) to other team members, freeing themselves to take on new roles (such as more involvement in working with service commissioners).

\section{Clinical governance}

Within the overall process of service resource allocation, the consideration of opportunity costs, marginal investment and performance optimisation must be aligned with considerations of quality and risk. This means that clinical governance must be a core component of all resource allocation decisionmaking (Onion, 2000).

\section{The role of the psychiatrist}

Within the context of the new NHS, psychiatrists can play a vital role in ensuring optimal resource allocation within mental health services. This means both understanding the basic principles involved and taking active steps to participate in the decisionmaking process. The final box in this article (Box 4) outlines the roles and requirements of psychiatrists if they are to engage fully in this process.
Box 4 The roles and requirements of the psychiatrist in resource allocation

Roles

- Actively contributing to service commissioning and planning - by defining areas of met and unmet need; advising on best service models; contributing to service business planning

- Actively contributing to mapping services - by defining current care (service) pathways; supporting baseline audits of existing resources; building understanding of cost of service components; identifying areas of inefficient resource use

- Focusing resource allocation - by more specifically matching resources to components of service pathways, such as best team skills mix, datasets for information systems to build knowledge, and best use of service buildings

- Establishing effective dialogue with managers - to allow improved flow of information, education and decision-making

Requirements

- Active inclusion by managers in setting service objectives and purpose - along with clear communication of agreed service plans

- Accessible financial information - in an understandable format, provided on a regular basis

- Active inclusion in commissioning and business planning process - with meetings arranged at times convenient for psychiatrists

- Integration of key processes - whereby there is a clear and transparent link between job planning, appraisal, service development and resource allocation. This may be a core role for medical managers

- Training and development resources - to build necessary competence in resource management and service development

\section{Declaration of interest}

M.D. is Director of Res Consortium, whose programmes include financial and resource management training for psychiatrists.

\section{References}

Ballantine, J., Brignall, S. \& Modell, S. (1998) Performance measurement and management in public health services: a comparison of UK and Swedish practice. Management Accounting Research, 9, 71-94. 
Bennett, A. R. (1994) Business planning: can the health service move from strategy into action? Journal of Management in Medicine, 8(2), 24-33.

Björk, S. \& Rosen, P (1993) Setting health care priorities in Sweden: the politicians' point of view. Health Policy, 26, 141-154.

Buchan, J., Ball, J. \& O'May F (2000) Determining Skill Mix in the Health Workforce: Guidelines for Managers and Health Professionals (Issues in Health Services Delivery paper no 3). Geneva: World Health Organization.

Butler, J. (1999) The Ethics of Healthcare Rationing. London: Cassell.

Cohen, D. (1994) Marginal analysis in practice: an alternative to needs assessment for contracting health care. BMJ, 309 781-785.

Cook, A. (1995) Management for doctors: management accounting. BMJ, 310, 381-385.

Daniels, N. (2000) Accountability for reasonableness. BMJ, 321, 1300-1301.

Department of Health (2004) The NHS Improvement Plan: Putting People at the Heart of Public Services (Cm 6268). London: TSO (The Stationery Office).

Department of Health (2005a) Commissioning a Patient-led NHS London: Department of Health.

Department of Health (2005b) NHS Reference Costs 2004. London: Department of Health.

Eccles, M. \& Mason, J. (2001) How to develop cost-conscious guidelines. Health Technology Assessment, 5(16).

Funk, M., Drew, N., Epping-Jordan, J., et al (2003) Mental Health Financing. Geneva: World Health Organization.

General Medical Council (1999) Management in Health Care: The Role of Doctors. London: GMC.

Kaplan, R. S. \& Norton, D. P. (1992) The balanced score card: measures that drive performance. Harvard Business Review, 70(1), 71-79.

Kren, L. (1992) Budgetary participation and managerial performance: the impact of information and environmental volatility. Accounting Review, 67, 511-526.

Lane, C., \& Bachmann, R. (eds) (2000) Trust within and between Organizations: Conceptual Issues and Empirical Applications. Oxford: Oxford University Press.

Mitton, C. \& Donaldson, C. (2003) Setting priorities and allocating resources in health regions: lessons from a project evaluating program budgeting and marginal analysis (PMBA). Health Policy, 64, 335-348.

Mitton, C. \& Donaldson, C. (2004) Health care priority setting: principles, practice and challenges. Cost Effectiveness and Resource Allocation, 2:3. DOI: 10.1186/1478-7547-2-3.

Myllykangas, M., Ryynanen, O, Lammintakanen, J., et al (2003) Clinical management and prioritisation criteria. Journal of Health Organization and Management, 17, 338-348.

Onion, C.W.R. (2000) Principles to govern clinical governance. Journal of Evaluation in Clinical Practice. 6, 405.

Purcell, J., Kinnie, N, Hutchinson, S., et al (2003) Understanding the People and Performance Link: Unlocking the Black Box. London: Chartered Institute of Personnel and Development.

Royal College of Psychiatrists \& National Institute for Mental Health in England (2005) New Ways of Working for Psychiatrists: Enhancing Effective, Person-centred Services through New Ways of Working in Multidisciplinary and Multiagency Contexts. Final Report 'But Not the End of the Story'. London: Department of Health.

Ruta, D., Mitton, C., Bate, A., et al (2005) Programme budgeting and marginal analysis: bridging the divide between doctors and managers. BMI, 330, 1501-1503.

Schon, D. (1983) The Reflective Practitioner: How Professionals Think in Action. London: Temple Smith.

Sensky, T. (2002) Knowledge management. Advances in Psychiatric Treatment, 8, 387-395.

Shah, A. \& Jenkins, R. (2000) Mental health economic studies from developing countries reviewed in the context of those from developed countries. Acta Psychiatrica Scandinavica, 101, 87-103.

Simpson, C. (2000) Commissioning mental health services: role of the consultant psychiatrist. Advances in Psychiatric Treatment $6,73-80$.
Thornicroft, G. \& Tansella, M. (2004) Components of a modern mental health service: a pragmatic balance of community and hospital care. Overview of systematic evidence. British Journal of Psychiatry, 185, 283-290.

Tyrer, P., Evans, K., Gandhi, N., et al (1998) Randomised controlled trial of two models of care for discharged psychiatric patients. BMJ, 316, 106-109.

\section{MCQs}

1 Effective resource allocation requires:

a some understanding of need

b no knowledge of strategic objectives

c active management

d a method of measuring performance

e inaccurate information.

2 Business planning within mental health services:

a is an important part of service development

b should not include psychiatrists

c is not concerned with resource allocation

$\mathrm{d}$ defines the relationship between clinical care and costs

e requires an in-depth knowledge of business techniques.

\section{An opportunity cost:}

a is the same as a marginal cost

$\mathrm{b}$ is part of business planning for a new clinic

c can relate to staff costs

d should include a consideration of equity

e is often ignored in service development.

4 Commissioning mental health services:

a will have a significant impact on the allocation of resources

b can be based on service pathways

c will become less focused on primary care

$\mathrm{d}$ can be done without any knowledge of reference costs

e may be supported by service mapping.

5 Psychiatrists can contribute to effective resource allocation through:

a understanding the basic cost of different service models

b knowing nothing about commissioning

c appraisal and job planning

$\mathrm{d}$ having regular accessible information on cost

e contributing to setting service objectives.

\section{MCQ answers}

$\begin{array}{lllllll}1 & & 2 & & 3 & 4 & 5 \\ \text { a T } & \text { a T } & \text { a F } & \text { a T } & \text { a T } \\ \text { b F } & \text { b F } & \text { b T } & \text { b T } & \text { b F } \\ \text { c T } & \text { c F } & \text { c T } & \text { c F } & \text { c T } \\ \text { d T } & \text { d T } & \text { d T } & \text { d F } & \text { d T } \\ \text { e F } & \text { e F } & \text { e T } & \text { e T } & \text { e T }\end{array}$

